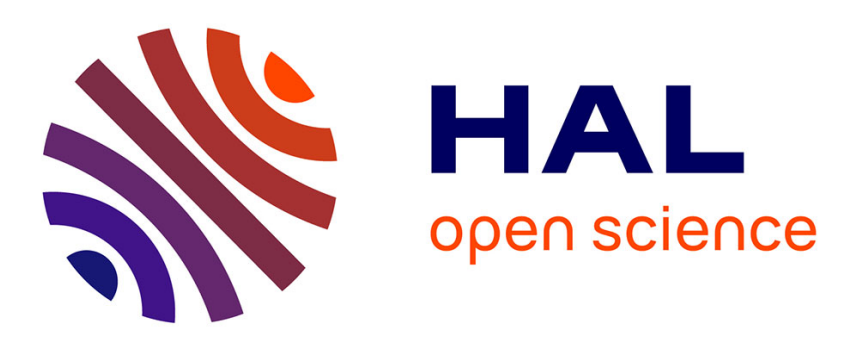

\title{
First-Principles Determination of Transference Numbers in Cryolitic Melts
}

Aïmen Gheribi, Mathieu Salanne, Didier Zanghi, Kelly Machado, Catherine Bessada, Patrice Chartrand

\section{- To cite this version:}

Aïmen Gheribi, Mathieu Salanne, Didier Zanghi, Kelly Machado, Catherine Bessada, et al.. FirstPrinciples Determination of Transference Numbers in Cryolitic Melts. Industrial and engineering chemistry research, 2020, 59 (29), pp.13305-13314. 10.1021/acs.iecr.0c02281 . hal-03014080

\section{HAL Id: hal-03014080 \\ https://hal.science/hal-03014080}

Submitted on 26 Nov 2020

HAL is a multi-disciplinary open access archive for the deposit and dissemination of scientific research documents, whether they are published or not. The documents may come from teaching and research institutions in France or abroad, or from public or private research centers.
L'archive ouverte pluridisciplinaire HAL, est destinée au dépôt et à la diffusion de documents scientifiques de niveau recherche, publiés ou non, émanant des établissements d'enseignement et de recherche français ou étrangers, des laboratoires publics ou privés. 


\section{First Principles Determination of Transference}

\section{Numbers in Cryolitic Melts}

Aïmen E. Gheribi, ${ }^{*, \dagger}$ Mathieu Salanne, ${ }^{\ddagger}$ Didier Zanghi, $₫$ Kelly Machado, Catherine Bessada, ${ }^{\top}$ and Patrice Chartrand ${ }^{\dagger}$

$\dagger$ Centre for Research in Computational Thermochemistry (CRCT) - Polytechnique Montréal, Department of Chemical Engineering, Box 6079, Station Downtown, Montréal, Qc , Canada, H3C $3 A 7$

$\ddagger$ Sorbonne Université, CNRS, Physico-chimie des électrolytes et nanosystèmes interfaciaux, PHENIX, F-75005, Paris, France

๑ CEMHTI, CNRS UPR3079, 1D Avenue de la Recherche Scientifique 45071 Orléans, France

E-mail: aimen.gheribi@polymtl.ca 


\begin{abstract}
The charge and electron transport properties of molten ionic systems are among the most relevant properties to consider in the control of several electrochemical processes. First-principles-based equilibrium molecular dynamics (EMD) can provide reliable predictions of both the total and partial charge transport properties. In this work we calculate the charge transport properties of the electrolytic bath $\left(\mathrm{Na}_{3} \mathrm{AlF}_{6}-\mathrm{AlF}_{3}-\mathrm{Al}_{2} \mathrm{O}_{3}\right)$ of the Hall-Héroult electrolysis cells. We predict both the individual and collective charge transport properties (total, partial conductivity and self diffusion coefficients) for 11 different compositions typical of industrial conditions via a series of EMD simulations. The predicted total and partial ionic conductivities and their composition dependence are compared to available experimental data. A good agreement is obtained for all studied compositions. From a more fundamental point of view, the microscopic aspect of the charge transport properties of cryolitic melts is discussed through its correlation to the local structure of different melts. Deviations between the calculated partial conductivities and those derived via the Nernst-Einstein approximation can be explained by the presence of strong short-range ordering within the melts.
\end{abstract}

\title{
Introduction
}

The partial electrical conductivity of electrolytes is one of the important properties to consider for controlling and optimizing the energy efficiency of electrochemical processes. The electrical conductivity of an electrolyte is in principle of ionic nature, nevertheless, when metals are dissolved in the electrolyte, which is the case for several industrial processes, electrons can be important contributors to the total conductivity. While experimental information on total ionic conductivity, $\sigma^{i o n}$, is generally widely available, a severe lack of data is observed for partial charge properties. Partial charge properties being the diffusion coefficients, $D_{i}^{0}$, and the partial charge conductivities, $\sigma_{i}^{i o n}$, most of the time represented through the so called "ionic transference number", defined by the ratio $\sigma_{i}^{i o n} / \sigma^{i o n}$. This lack of data is 
due to experimental limitations. Indeed, contrary to the total ionic conductivity, measuring the partial ionic conductivity is not straightforward. The experimental measurement of the total ionic conductivity of electrolytes is made through impedance measurements employing inert electrodes. ${ }^{1}$ Measures of partial ionic conductivity are obtained via the Hittorf method which is difficult to implement, especially at high temperature. The total ionic conductivity of cryolitic melts as a function of temperature and additives amounts is in general well known and several critical assessments of available set of experimental data and their incorporation into self-consistent databases are reported in the literature. However, almost no experimental data for the partial charge transport properties $\left(t_{i}\right.$ 's and $D_{i}^{0}$ 's) of cryolitic melts are reported in the literature. Finally, the adaption of pulsed field gradient nuclear magnetic resonance experiments to high temperature liquids ${ }^{2}$ allowed to obtain the self-diffusion coefficients in a variety of molten salts but the amount of available data remains relatively scarce.

In the case of cryolitic melts (in which the main components are $\mathrm{NaF}$ and $\mathrm{AlF}_{3}$ ), Rollet and Gobet ${ }^{3,4}$ measured the self diffusion coefficient of the $\mathrm{Na}_{3} \mathrm{AlF}_{6}$ liquid near the melting temperature. Hives and Fellener ${ }^{5,6}$ determined the transference numbers of $\mathrm{Na}^{+}$based on the Hittorf method. In addition, in cryolitic melts saturated in alumina $\left(\mathrm{NaF}-\mathrm{AlF}_{3}-\mathrm{Al}_{2} \mathrm{O}_{3}\right)$ , Franck and Foster ${ }^{7}$ and Tual and Rolin ${ }^{8,9}$ estimated the transference number of $\mathrm{Na}^{+}$. In a nutshell, the properties where shown to depend widely on the cryolitic ratio (CR), defined as $\mathrm{CR}=x_{\mathrm{NaF}} / x_{\mathrm{AlF}_{3}}$ where $x$ is the molar fraction of a given salt. They showed that (i) in neutral $(\mathrm{CR}=3)$ and basic $(\mathrm{CR} \geq 3)$ cryolitic melts, the electrical current is almost completely carried by $\mathrm{Na}^{+}$ions $\left(t_{\mathrm{Na}^{+}} \simeq 1\right)$ and (ii) in acidic cryolitic melts $(\mathrm{CR} \leq 3)$, the contribution of free $\mathrm{F}^{-}$ions become significant. For example, for a $\mathrm{CR}$ of about 2.5, $t_{\mathrm{Na}^{+}}$lies in the range 0.90 to 0.95 . The predominance of $\mathrm{Na}^{+}$ions in the total electrical current within $\mathrm{NaF}-\mathrm{AlF}_{3}$ was recently confirmed by Gheribi et al. ${ }^{10}$ via a series of EMD simulations. In other words, the few experimental data points on partial charge transport properties is insufficient to build a temperature and composition dependent models for both ionic transference numbers and self diffusion coefficients. 
To overcome the lack of experimental data on charge transport, thermal transport, dynamics or structural properties, a very common modern strategy is to predict them utilising first-principles-based atomistic simulations. The accuracy of atomistic level simulations increased significantly during last decade, and they can now be considered to be predictive for a wide range of molten salts. In the present paper, we propose to determine the charge transport properties of cryolitic melts for composition of industrial interest.

From a more fundamental point of view, understanding the microscopic aspects of the charge transport properties and their relation with the local structure is also an important challenge. While the total conductivity and the self diffusion coefficients are in general accurately predicted by EMD, finding the partial conductivity remains difficult. Most of the time, the partial ionic conductivity is determined through a Nernst-Einstein approximation, i.e by neglecting the correlation between the various species. Nevertheless molten salts are intrinsically strongly correlated systems, with a significant short range ordering. The interionic interactions influence importantly the partial conductivity. For example, in cryolitic melts, the fact that experiments show that electrical current is almost entirely carried by $\mathrm{Na}^{+7-9}$ ions indicate a strong correlation between other ions $\left(\mathrm{O}^{2^{-}}, \mathrm{F}^{-}\right.$and $\left.\mathrm{Al}^{3^{+}}\right)$. In order to take into account the effects of the interionic correlations upon the partial conductivity, we have proposed in recent works ${ }^{10,11}$ an original theoretical approach, in which all the quantities of interest are determined within the Green-Kubo formulation of the total ionic conductivity. ${ }^{12}$ From this approach, we derived the partial conductivity of ions within the $\mathrm{NaF}-\mathrm{AlF}_{3}$ melts $^{10}$ and found a good agreement with the available experimental data. ${ }^{5,13}$ Besides demonstrating the reliability of our approach for cryolitic melts, we have shown the strong influence of the short range ordering on the total and partial ionic conductivities. The contribution of ions forming coordination complexes $\left(\mathrm{AlF}_{x}^{3-x}\right.$ and $\left.\mathrm{Al}_{2} \mathrm{~F}_{m}^{6-m}\right)$ on the total conductivity is negligible. It is also important to note that even for pure $\mathrm{NaF}$, a deviation from the Nernst-Einstein approximation of about $25 \%$ was found from our simulations, which is consistent with experiments of Grjotheim et al. ${ }^{14,15}$ This indicates that ions correlation is significant, even for 
simple ionic systems, thereby rejecting the Nernst-Einstein approximation for any ionic mixtures. In this work, in addition to predicting values for partial charge transport properties of key cryolitic melts of industrial interest, the microscopic aspect of the charge transport will be investigated through the partial charge transport-local structure correlation, in particular with the amount of coordination complexes within the melts. The deviation of the partial conductivity from what is obtained via the Nernst-Einstein approximation will enable us to determine the relative contributions of the ionic correlations and of the self-diffusion. These two contributions are then discussed in terms of local structure to establish a clear picture of the microstructure aspect of the charge transport properties within cryolitic melts.

\section{Theory and Modelling}

Interaction potentials The potentials employed to simulate the phase trajectories were developed by Machado et al. ${ }^{16}$ The potentials formalism is well documented ${ }^{17-19}$ and will not be detailed here (the reader is referred to these references for a detailed description of the formalism). In summary, the potential consists in a pair of interaction terms of Born-Mayer form, together with the account of Coulomb, dispertion and polarization interaction: ${ }^{17-19}$

$$
V=\sum_{i<j}[\frac{q_{i} q_{j}}{r_{i j}}+B_{i j} e^{-\alpha_{i j} r_{i j}} \underbrace{f_{i j}^{6}\left(r_{i j}\right) \frac{C_{i j}^{6}}{r_{i j}^{6}}-f_{i j}^{8}\left(r_{i j}\right) \frac{C_{i j}^{8}}{r_{i j}^{8}}}_{V_{\text {disp. }}}]+V_{p o l .}\left(\alpha_{i}, p_{i}\right)
$$

$V_{\text {disp. }}$ describes the dispersion interactions where $C_{i j}^{6}$ and $C_{i j}^{8}$ are the dispersion coefficients and $f_{i j}^{(n)}$ the dispersion damping function given by: ${ }^{20}$

$$
f_{i j}^{(n)}=1-e^{-b_{i j}^{n} r_{i j}} \sum_{k=0}^{n} \frac{\left(b_{i j}^{n} r_{i j}\right)^{n}}{k !}
$$


The polarisation potential, $V_{p o l}$, is a many-body term dependant on a key parameter: the ion polarizability $\left(\alpha_{i}\right)$. The induced dipoles $\left(p_{i}\right)$ are additional degrees of freedom of the simulation. The polarization term reflects the distortion of electronic density in response to the electric field caused by all other ions. The dipoles are determined at each simulation time step by minimizing the total polarization energy. ${ }^{21}$ Note that the potentials parameters were determined from first-principles density functional theory (DFT) calculations through a generalized "force-matching" technique. ${ }^{22}$

Simulation details The simulations were carried at $1260 \mathrm{~K}$ with 720 to 728 ions in the simulation box using periodic boundary conditions and minimum image convention. A first series of EMD simulation was perfomed in the isobaric-isothermal statistical ensemble (NPT) at $1260 \mathrm{~K}$ and at $P=10^{5} \mathrm{~Pa}$ to determine the equilibrium density and to generate thermally equilibrated configurations. Then, starting with a thermally equilibrated initial configuration, a second series of EMD simulations was performed on the canonical statistical ensemble (NVT). The volume of the simulation box for NVT simulations was fixed to the average volume determined by the NPT simulations. During the simulations, in both the

NPT and NVT ensembles, the temperature is controlled with a Nosé-Hoover thermostat ${ }^{23}$ and for simulations in the NPT ensemble, the pressure is controlled by an extension of the Martyna barostat. ${ }^{24}$ The relaxation time is $0.5 \mathrm{ps}$ for both thermostat and barostat. The Verlet algorithm ${ }^{12}$ with a time step of 1 fs was employed for the integration of Newton's equations of motion. The total simulation time was $1.5 \mathrm{~ns}$ for NPT and and $5 \mathrm{~ns}$ for NVT simulations. Then, from the simulated phase trajectory in the NVT ensemble, we calculated the total and partial charge transport properties.

Determination of the charge transport properties from simulated phase trajectories Under periodic boundary conductions (PBC), the self diffusion coefficient of species $i, D_{i}^{P B C}$, is defined as the slope of the mean-squared displacements over time of the 
species:

$$
D_{i}^{0, P B C}=\lim _{t \rightarrow \infty} \frac{\partial}{\partial t} \frac{\left\langle|\mathbf{r}(t)-\mathbf{r}(0)|^{2}\right\rangle}{6}
$$

where $r(t)$ denotes $i$ 's ion trajectories at time $\mathrm{t}$ and $r(0)$ its initial position in the cartesian space. The MSD was fitted in the long time motion region $(t \succeq 10 p s)$ to ensure its linearity with time and thus avoid collision free motion. $D_{i}^{P B C}$ is not strictly speaking the "true" self diffusion coefficient. Indeed, upon PBC, the self diffusion coefficient depends on the box size, $L$. Yeh and Hummer ${ }^{25}$ have proposed a correction to $D_{i}^{P B C}$ allowing to obtain the "true" self diffusion coefficient $D_{i}^{0}$ according to the relationship:

$$
D_{i}^{0}=D_{i}^{P B C}+\xi \frac{k_{B} T}{6 \pi \eta L}
$$

where $k_{B}$ is the Boltzmann constant and $\xi$ a constant that can be approximated to $2.838, \eta$ is the shear viscosity which, according to the Green-Kubo formalism, can be calculated via the following relation: ${ }^{12}$

$$
\eta=\beta V \int_{0}^{\infty}\left\langle\sigma_{\alpha \beta}(0) \sigma_{\alpha \beta}(t) \mathrm{d} t\right.
$$

where $\beta=1 / k_{B} T$ and $V$ is the equilibrium volume. The integrand are the autocorrelation function of the anisotropic elements of the stress tensor $\sigma_{\alpha \beta}$. An average over the five independent components of the stress tensor is calculated to improve statistics.

The total ionic conductivity is obtained from the charge slope of the total MSD of the charge density versus time: ${ }^{26}$

$$
\sigma^{i o n}=\frac{1}{6} \frac{\beta e^{2}}{V} \lim _{t \rightarrow \infty} \frac{\partial}{\partial t}\left\langle\left\{\sum_{i} Z_{i}\left[\mathbf{r}_{i}(t)-\mathbf{r}_{i}(0)\right]\right\}^{2}\right\rangle
$$

where $Z_{i}$ is the formal charge of ion $i$.

Let us now discuss the core of the present study: predicting the partial ionic conductivity. The total conductivity can be decomposed into individual contributions of each $N$ ions in 
the molten mixture:

$$
\sigma^{i o n}=\sum_{i=1}^{N} \sigma_{i}^{i o n}
$$

The partial conductivity of $i$ can be formulated as: ${ }^{10}$

$$
\sigma_{i}^{i o n}=\frac{1}{6} \frac{\beta e^{2}}{V} \lim _{t \rightarrow \infty} \frac{\partial}{\partial t}\left\langle Z_{i}^{2} \Delta_{i}^{2}(t)+\sum_{j \neq i} \omega_{i-j}^{i} Z_{i} Z_{j} \Delta_{i}(t) \Delta_{j}(t)\right\rangle
$$

where $\Delta_{i}(t)$ represents the displacement of all ions of type $i$ and $\omega_{i-j}^{j}$ is a constant introduced to quantify the mutual effect upon the total conductivity generated by the various $i-$ $j$ pairs. It is related to the magnitude of the interferences from other species on ion $i$. Obviously, for a given pair $i-j$, the $\omega_{i-j}^{j}$ 's must satisfy the following constraint: $\omega_{i-j}^{i}+$ $\omega_{i-j}^{j}=2$. The significance of the $\omega_{i-j}^{j}$ 's is discussed in a prior publication ${ }^{10}$ in terms of its microscopic aspects. It has been proposed ${ }^{10}$ that for fully dissociated mixtures (e.g. $\mathrm{NaCl}$ ), the free cations species take full advantage of the ion-ion interferences at the expense of anions, i.e $\omega_{a n .-c a t .}^{a n .}=0$ and $\omega_{a n \text {.cat. }}^{\text {cat. }}=2$ (where an. stands for anion and cat. for cation). When a simple molten salt mixture is formed of more than one cation (such as $\mathrm{NaCl}-$ $\mathrm{KCl}$ ), the corresponding interference terms should be equally split between the two cations:

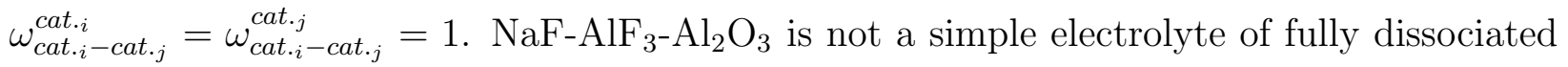
ions but a system with a strong short range ordering (SRO) forming several coordination complexes. Within the $\mathrm{NaF}-\mathrm{AlF}_{3}-\mathrm{Al}_{2} \mathrm{O}_{3}$ electrolyte, $\mathrm{Al}^{3+}$ cations are interacting with both $\mathrm{F}^{-}$and $\mathrm{O}^{2^{-}}$anions to form negatively charged associates: fluorites of the form $\mathrm{AlF}_{3+n}^{n-}$ $(1 \leq n \leq 4)$, aluminates of the form $\mathrm{AlO}_{3+m}^{(3+2 m)-}(1 \leq m \leq 4)$ and oxyfluoroaluminates of the form $\mathrm{Al}_{h} \mathrm{O}_{k} \mathrm{~F}_{l}^{(3 h-2 k-l)^{-}}(2 \leq h \leq 3,1 \leq k \leq 2$ and $6 \leq l \leq 11) .{ }^{27}$ The coordination complex formed by $\mathrm{Al}^{3+}, \mathrm{O}^{-}$and $\mathrm{F}^{-}$can be considered as a specific anionic species. It is therefore natural that these 3 ions have similar interference contributions on the partial conductivity. Considering this, the ansatz allowing the formulation of $\omega_{i-j}^{j}$ 's in the $\mathrm{NaF}-\mathrm{AlF}_{3}$ system can be generalized in $\mathrm{NaF}-\mathrm{AlF}_{3}-\mathrm{Al}_{2} \mathrm{O}_{3}$ as follows:

(i) $\mathrm{Na}^{+}$cations can be considered as free species, therefore their partial conductivity is 
enhanced by all ionic interferences of other species and then, for $\mathrm{Na}^{+}$, the $\omega_{i-j}^{j}$ 's are given by:

$$
\left\{\begin{array}{l}
\omega_{O^{2^{-}-N a^{+}}}^{O^{-}}=\omega_{F^{-}-N a^{+}}^{F^{-}}=\omega_{A l^{3}{ }^{3^{+}}-N a^{+}}=0 \\
\omega_{O^{2^{-}-N a^{+}}}^{N a^{+}}=\omega_{F^{-}-N a^{+}}^{N a^{+}}=\omega_{A l^{3+}-N a^{+}}^{N a^{+}}=2
\end{array}\right.
$$

(ii) $\mathrm{Al}^{3+}$ are interacting with both $\mathrm{O}^{-}$and $\mathrm{F}^{-}$anions to form coordination complexes, the interferences contributions upon the partial conductivities mutually neutralise themselves, and thus:

$$
\left\{\begin{array}{l}
\omega_{O^{2^{-}}-A l^{3^{+}}}^{2^{-}}=\omega_{F^{-}-A l^{3^{+}}}^{F^{-}}=1 \\
\omega_{O^{2^{-}-} A l^{3^{+}}}^{A l^{+}}=\omega_{F^{-}-A l^{3^{+}}}^{A l^{+}}=1
\end{array}\right.
$$

(iii) both $\mathrm{O}^{2^{-}}$and $\mathrm{F}^{-}$are simultaneously interacting only in presence of coordination complexes formed by $\mathrm{Al}^{3+}$, therefore there is also no mutual interference contribution upon the partial conductivity, and the $\omega_{i-j}^{j}$ 's are given by:

$$
\omega_{O^{2-}-F^{-}}^{F^{-}}=\omega_{O^{2-}-F^{-}}^{O^{-}}=1
$$

Let us now discuss the most widely used method to estimate the partial conductivities of ionically-bonded molten system, namely the Nernst-Einstein approximation (N-E), which assumes that the ions motion within an electrolyte are uncorrelated. In this case, the ionic mobility is directly proportional to the self diffusion coefficient and thus to the partial conductivity:

$$
\sigma_{i}^{N-E}=\frac{\beta e^{2}}{V} N_{i} Z_{i}^{2} D_{i}^{0}
$$

where $N_{i}$ and $Z_{i}$ are respectively the number charge of the ion of type $i$ and its number of charge. Then, the total ionic conductivity in the Nernst-Einstein approximation is given by:

$$
\sigma^{N-E}=\sum_{i} \sigma_{i}^{N-E}
$$

Lastly, the reliability of the above formalism when predicting the partial charge properties 
was demonstrated for different types of systems: from those with negligible short range ordering, for example FLiNaK to systems with pronounced short range ordering, i.e systems forming ordination complexes such as molten alumina or cryolite. ${ }^{10,11}$ Note that same type of potentials allow also an accurate prediction of the thermal conductivity of molten salts, ${ }^{28-31}$ which has a pronounced thermoelectric component, i.e. the coupling effect between the charge and the thermal transport.

\section{Results and discussion}

For 11 selected compositions of industrial interest (C1, C2...C11) at $1260 \mathrm{~K}$, we have calculated the total and partial charge transport properties via a series of EMD simulations, described above, and reported them in Table 1. Using prevailing lingo in the aluminium industry, the studied range of composition is defined as:

$$
\left\{\begin{array}{l}
2 \leq C R \leq 3 \\
1 \leq w t . \% \mathrm{Al}_{2} \mathrm{O}_{3} \leq \text { saturation }
\end{array}\right.
$$

Where $w t . \% \mathrm{Al}_{2} \mathrm{O}_{3}$ represents the weight percent of alumina. Equilibrium calculations via the FactSage software and databases ${ }^{32}$ indicate that at $1260 \mathrm{~K}$, for the set of compositions considered in this work, the concentration of alumina at saturation is nearly constant varying from 10.03 wt.\%, for C3, to 10.7 wt.\% for C8. Therefore only C10 and C11 are close to alumina saturation. For practical reasons, it is preferable to highlight the relative contribution of each ion to the total conductivity rather than their absolute values. Therefore, instead of reporting the partial conductivity values, we report in Table 1 the transference numbers (or external transport numbers), $t_{i}^{i o n}$, defined as the ratio:

$$
t_{i}^{i o n}=\frac{\sigma_{i}^{i o n}}{\sigma^{i o n}}
$$


The standard error associated with each calculated property is calculated by the error block averaging method. ${ }^{33,34}$ The number of blocks is proportional to the simulation time and obtained after a convergence test. For clarity purposes, errors are only displayed on the figures. The calculated density, total ionic conductivity and viscosity are compared with critical assessments, to best represent critically reviewed experimental data. For other properties there is no possible comparison, as no experimental values are reported in the literature. 


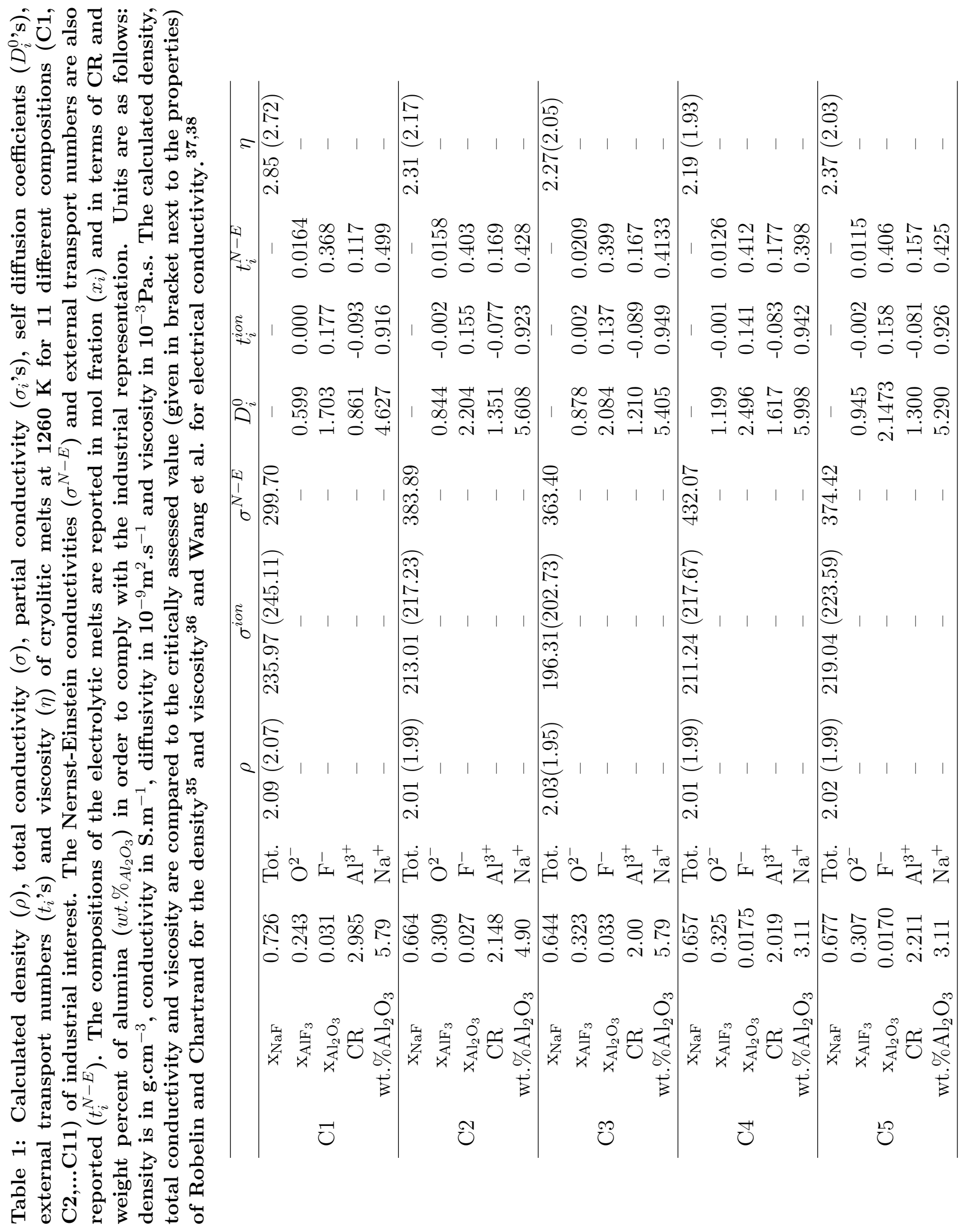




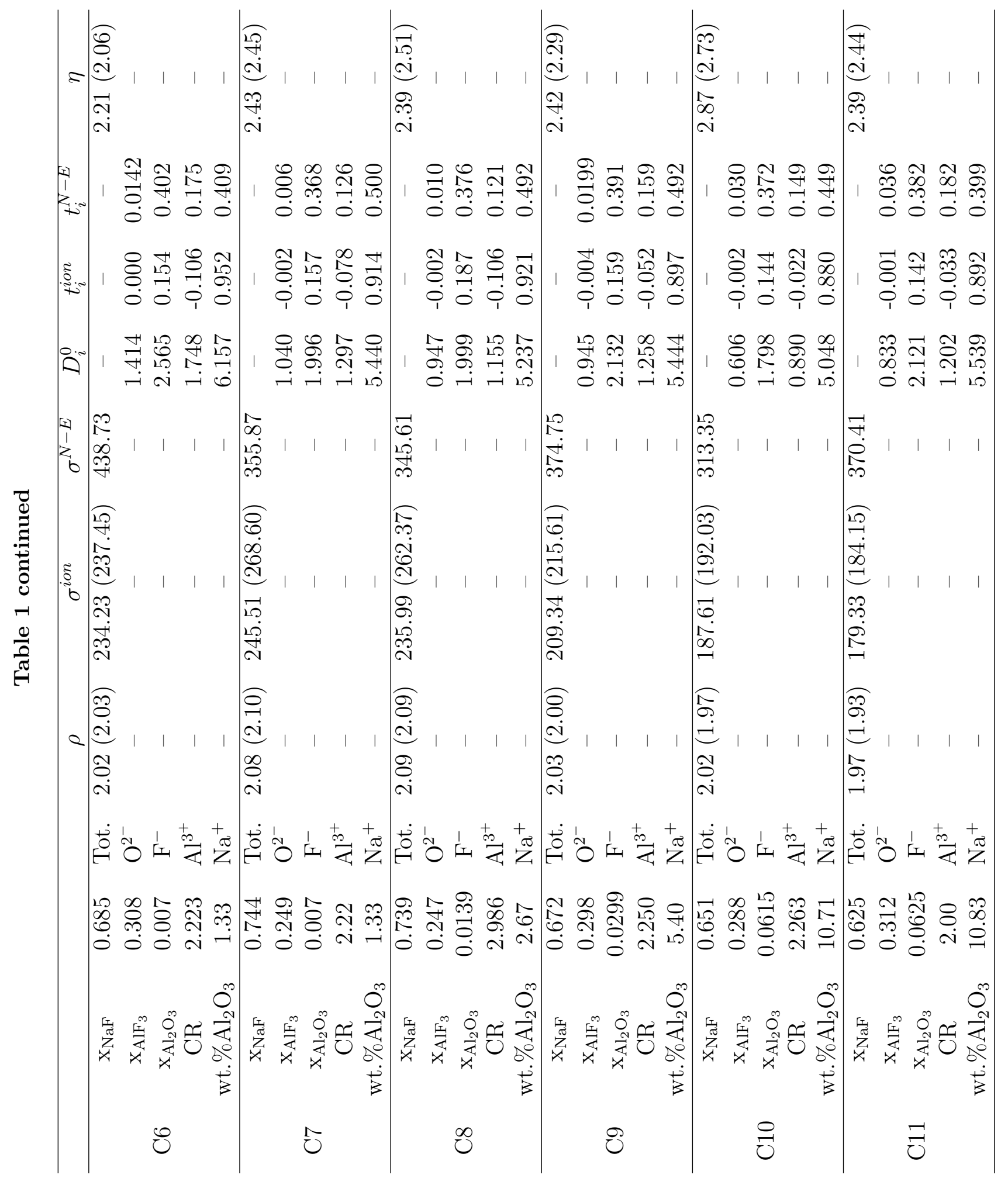


For the 11 compositions, the calculated density, ionic conductivity and viscosity show a very good agreement with critically assessed data. The discrepancies are below the typical experimental errors for these properties. A similar agreement was obtain by Machado et al. ${ }^{16}$ for cryolitic melts of $\mathrm{CR}=2.2$ and 3.0 with up to 8 wt.\% of alumina. This high predictive capability demonstrates the reliability of the present force field employed to represent the interaction within $\mathrm{NaF}-\mathrm{AlF}_{3}-\mathrm{Al}_{2} \mathrm{O}_{3}$. In the current paper, we are not focusing our discussion on integral properties, as they were already discussed by Machado et al., ${ }^{16}$ but rather on the partial charge properties. Having said that, the reliability of the present EMD simulations when predicting the dynamical and transport properties of the 11 studied cryolitic melts can be illustrated in Figure 1 through pairwise of calculated vs. critically assessed properties. Even though the density is slightly overestimated for a few compositions, the predictive capability of the force field used is clearly demonstrated with an high accuracy obtained for both ionic conductivity and viscosity. This suggests a similar good predictive capability of EMDs for the partial charge transport properties. Note that a similar accuracy in predicting the ionic conductivity and density was achieved for simple cryolitic melts at $1293 \mathrm{~K}$ for $C R \leq 1^{10}$ using the same force field. 

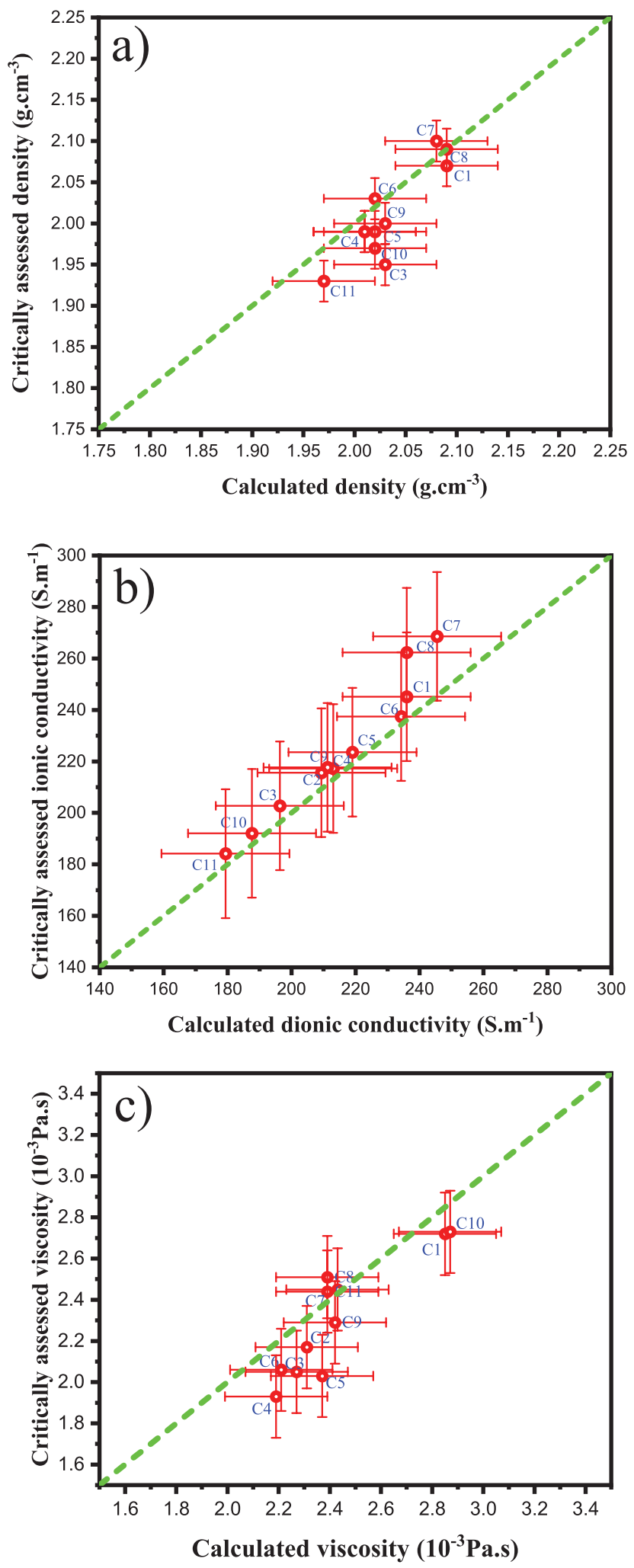

Figure 1: Pairwise relationship between EMD calculations and critical assessments for density (a), ionic conductivity (b) and viscosity (c) for the the 11 studied cryolitic melts at $1260 \mathrm{~K}$. The critically assessed data are from, ${ }^{3536}$ and ${ }^{37,38}$ respectively for density, ionic conductivity and viscosity. The errors on the EMD data were obtained with the error block averaging method ${ }^{33,34}$ while the error bars on the critically assessed properties represent the average discrepancy between the different experimental datasets considered in the given assgssment ${ }^{37}$ 


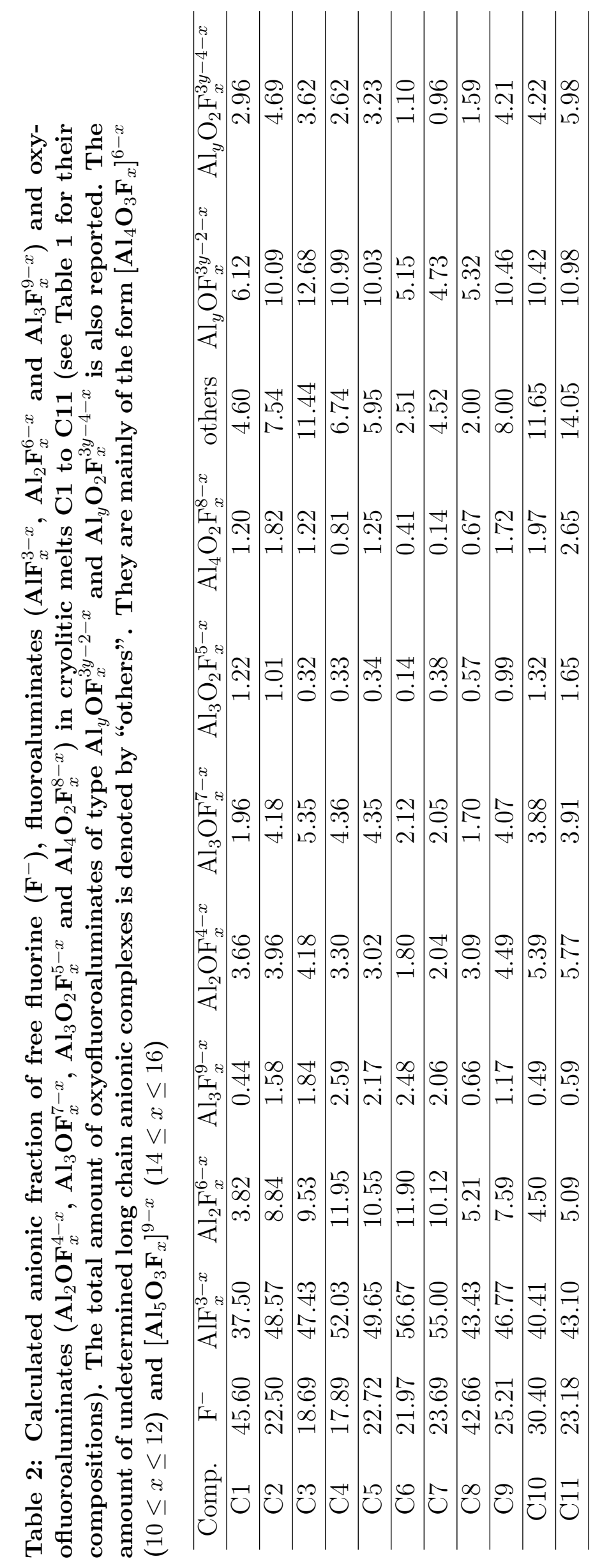




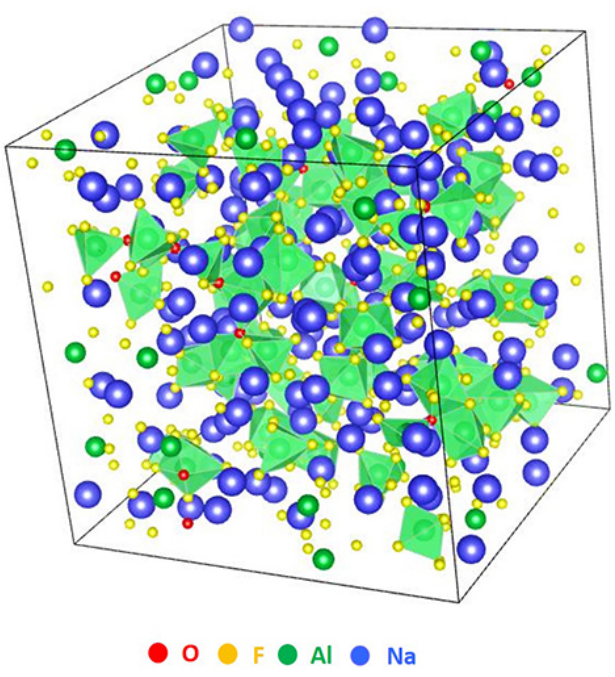

a)

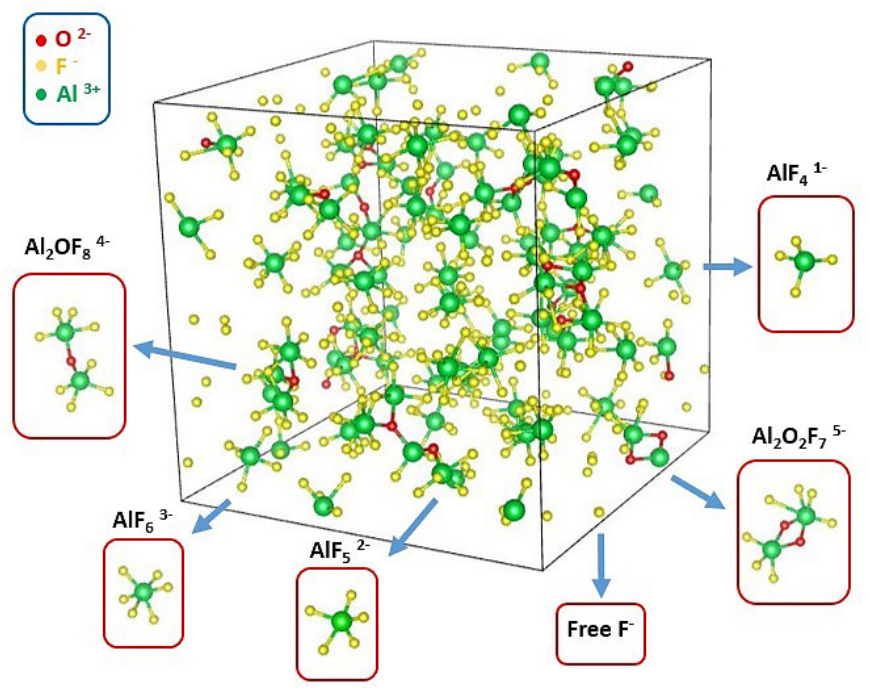

b)

Figure 2: Visualisation of one snapshot of atomic distribution (a) and coordination anionic complexes (b) within the cryolitic melt C2 from the simulated phase trajectory in the NVT ensemble. In figure b, sodium atoms were purposely omitted for reasons of clarity, as they do not evolve in any coordination complexes.

Let us now examine the transference numbers (external transport numbers). First, it is important to note that the average error obtained for transference numbers is relatively significant, about 0.05. Considering this range of uncertainty, the EMD calculations of transference numbers can be summarized, for the 11 cryolitic melts, as follows:

$$
\left\{\begin{array}{l}
t_{O^{2^{-}}}^{i o n} \simeq 0 \\
t_{F^{-}}^{i o n}=0.15 \pm 0.05 \\
t_{A l^{+}}^{i o n}<0(-0.05 \pm 0.05) \\
t_{N a^{+}}^{i o n}=0.90 \pm 0.05
\end{array}\right.
$$

In other words, within cryolitic melts, $\mathrm{Na}^{+}$dominates the total ionic conduction while $\mathrm{O}^{2-}$ does not contribute at all, $\mathrm{F}^{-}$has a limited (but non negligible) contribution and $\mathrm{Al}^{3^{+}}$has a small but negative effect, which is at first glance counter-intuitive. In our prior work, ${ }^{10}$ a negative transference has been also found for simple $\mathrm{NaF}-\mathrm{AlF}_{3}$ cryolitic melts at $1293 \mathrm{~K}$ 
for $x_{\mathrm{AlF}_{3}} \geq 0.15$. Moreover, the magnitude of the transference number of $\mathrm{Al}^{3+}$ was found to be small, less than about $5 \%$. This can be explained by the fact that $\mathrm{Al}^{3^{+}}$involves larger fluoroaluminates anions $\left(\left[\mathrm{AlF}_{x}\right]^{3-x}\right)$ (compared to $\mathrm{Na}^{+}$) migrating towards the anode, while a free $\mathrm{Al}^{3^{+}}$cation moves in the opposite direction, i.e towards the cathode. Note that a negative transference number is not an anomaly but a consequence of a specific physical process. It was highlighted in the $1940 \mathrm{~s}^{39}$ in aqueous solutions, and later in different electrolytes, ${ }^{40}$ polymer $^{41-43}$ and in solid solution as well. ${ }^{44}$ The partial charge transport properties of the cryolitic melts depends on both $\mathrm{CR}$ and aluminium content. Behind this composition dependence, there is an evolution of the local structure with composition. Indeed, from a microscopic point of view, the transport properties are closely linked, to varying degree, to the local structure. Therefore, to quantitatively discuss the composition dependence of the charge transport properties, the local structure, i.e. the speciation of the melts must be first characterised. The speciation of cryolitic melts is defined by the amount of free species and all the formed coordination complexes. The $\mathrm{Na}^{+}$cation remains free, i.e it is not associated to any coordination complex, while $\mathrm{Al}^{3^{+}}$complexes with both $\mathrm{F}^{-}$and $\mathrm{O}^{2^{-}}$ form fluoroaluminates and oxofluoroalumiates anion complexes. To determine speciation in molten mixtures containing 2 anions $\left(\mathrm{O}^{2^{-}}, \mathrm{F}^{-}\right)$and 2 cations $\left.\left(\mathrm{Al}^{3^{+}}, \mathrm{Na}^{+}\right]\right)$, we performed a statistical analysis of the ion trajectories from our molecular dynamics simulations. For each $\mathrm{Al}^{3^{+}}$ion contained in our simulation boxes, we counted the number of closest neighbours $\mathrm{O}^{2-}$ and $\mathrm{F}^{-}$. For this purpose, we defined coordination spheres whose cut-off radius correspond to the first minimum of the radial distribution functions (RDFs) of the atomic pairs Al-O, $\mathrm{Al}-\mathrm{F}$ and $\mathrm{Al}-\mathrm{Al}$ respectively. These functions are obtained from the position of the atoms at each instant during the simulation. By successively testing Al-Al, Al-O and then Al-F distances as a function of the first minima of the RDFs of the corresponding ion pairs, we determined the $\mathrm{O}^{2-}$ that link the $\mathrm{Al}^{3^{+}}$together and the $\mathrm{F}^{-}$that surround these $\mathrm{Al}^{3^{+}}$ions. The application of these geometrical criteria allowed us to identify several types of anionic species in the bath: $\mathrm{F}^{-},\left(\mathrm{AlF}_{x}\right)^{3-x},\left(\mathrm{Al}_{2} \mathrm{~F}_{x}\right)^{6-x},\left(\mathrm{Al}_{y} \mathrm{OF}_{x}\right)^{3 y-2-x}$, and $\left(\mathrm{Al}_{y} \mathrm{O}_{2} \mathrm{~F}_{x}\right)^{3 y-4-x} \ldots$. 
The anionic fraction of free $\mathrm{F}^{-}$, fluoroaluminates and oxofluoroalumiates is presented in Table 2. The main identified fluoroaluminates anions species are $\left[\mathrm{AlF}_{x}\right]^{3-x}$ and $\left[\mathrm{Al}_{2} \mathrm{~F}_{x}\right]^{6-x}$ although a negligible amount of $\left[\mathrm{Al}_{3} \mathrm{~F}_{x}\right]^{9-x}$ may be observed. The oxofluoroalumiates anions can be placed into two families: the $\left[\mathrm{Al}_{y} \mathrm{OF}_{x}\right]^{3 y-2-x}$ anions and $\left[\mathrm{Al}_{y} \mathrm{O}_{2} \mathrm{~F}_{x}\right]^{3 y-4-x}$ anions. It should be noted that the speciation of cryolitic melts is increasingly complex, as the alumina concentration increases. Indeed, since $\mathrm{Al}^{3+}$ complexes with both $\mathrm{F}^{-}$and $\mathrm{O}^{2-}$, longer chains of oxofluoroalumiates can be formed as the amount of $\mathrm{Al}^{3^{+}}$, therefore alumina, increases. These long oxofluoroalumiates are identified in Table 2 by the term "others" and they are of the form $\left[\mathrm{Al}_{4} \mathrm{O}_{3} \mathrm{~F}_{x}\right]^{6-x}$ anions with $10 \leq x \leq 12$, even though some $\left[\mathrm{Al}_{5} \mathrm{O}_{3} \mathrm{~F}_{x}\right]^{9-x}$ anions with $14 \leq x \leq 16$ are likely to appear at very high alumina concentration, close to saturation. Lastly, it is important to note the absence of $\left[\mathrm{Al}_{2} \mathrm{O}_{2} \mathrm{~F}_{x}\right]^{2-x}$ anion complexes within the melts, whatever the alumina concentration. To illustrate the local structure of cryolitic melts, we show in Figure 2 the distribution of anionic complexes for a given configuration (taken at an arbitrary simulation time) of $\mathrm{C} 2$.

From a structural point of view, the null transference number of $\mathrm{O}^{2^{-}}$within cryolitic melts is due to the fact that $\mathrm{O}^{2-}$ complexes with heavy and large oxofluoroaluminates entities, for which the electrical mobility is negligible. From a microscopic point of view, this null partial conductivity is due to the total cancellation of the uncorrelated partial conductivity of $\mathrm{O}^{2-}$, defined as: $\sigma_{O}^{i o n}=\left(\beta e^{2} / 6 V\right) \lim _{t \rightarrow \infty} \partial\left(Z_{O}^{2} \Delta_{O}\right) / \partial t$ (see Eq.8), by the electrostatic interferences with other ions (quantified by the $\omega_{i j}^{i}$ 's matrix), in particular with $\mathrm{Na}^{+}$. Thereafter, the transference numbers of $\mathrm{F}^{-}, \mathrm{Al}^{3+}$ and $\mathrm{Na}^{+}$are shown in Figure 3, 4 and 5 respectively. They are represented along with relevant local structure information related to the evolution of the corresponding transference number.

Let us start with $\mathrm{F}^{-}$, in the range $2 \leq C R \leq 3$, the fraction of free $\mathrm{F}^{-}$in cryolitic melts exhibits a quasi linear behaviour with CR (Figure 3 (a)). As a result, in the same range of composition, the $\mathrm{F}^{-}$transference has also a nearly linear dependence with $F^{-}$fraction and, by extension, with $\mathrm{CR}$ as well. Quantitatively, the composition dependence of the $\mathrm{F}^{-}$ 

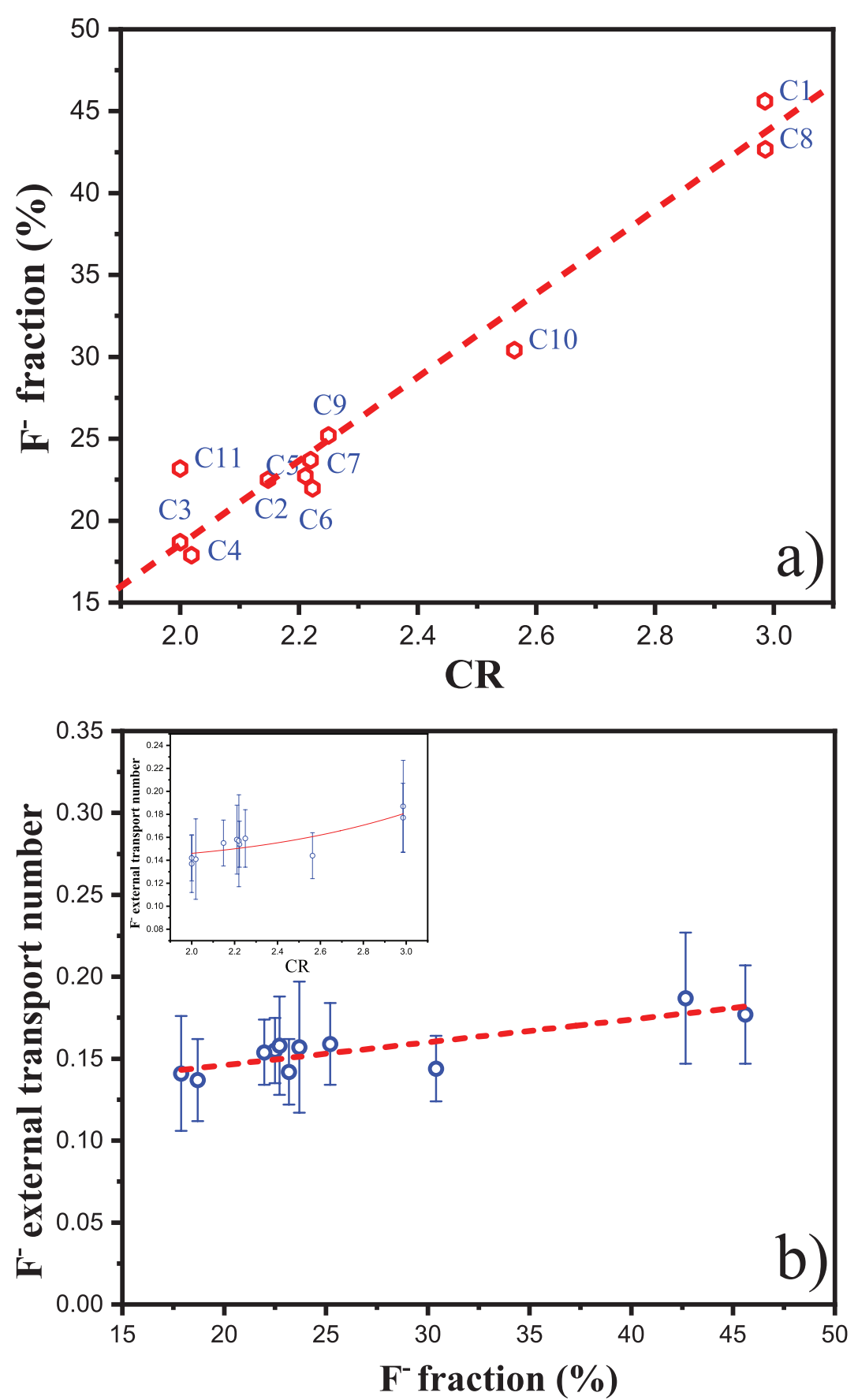

Figure 3: Calculated fraction of free $\mathrm{F}^{-}$as a function of $\mathrm{CR}(\mathrm{a})$ and representation of $\mathrm{F}^{-}$transference number as a function of free $\mathrm{F}^{-}$fraction (b). The insight Figure represents the $\mathrm{F}^{-}$transference number as a function of $\mathrm{CR}$ while The dashed line represents a linear fitting of $t_{F^{-}} \mathrm{vs}^{-} \mathrm{F}^{-}$fraction. The dashed line represents a B-spline interpolation of the data. 

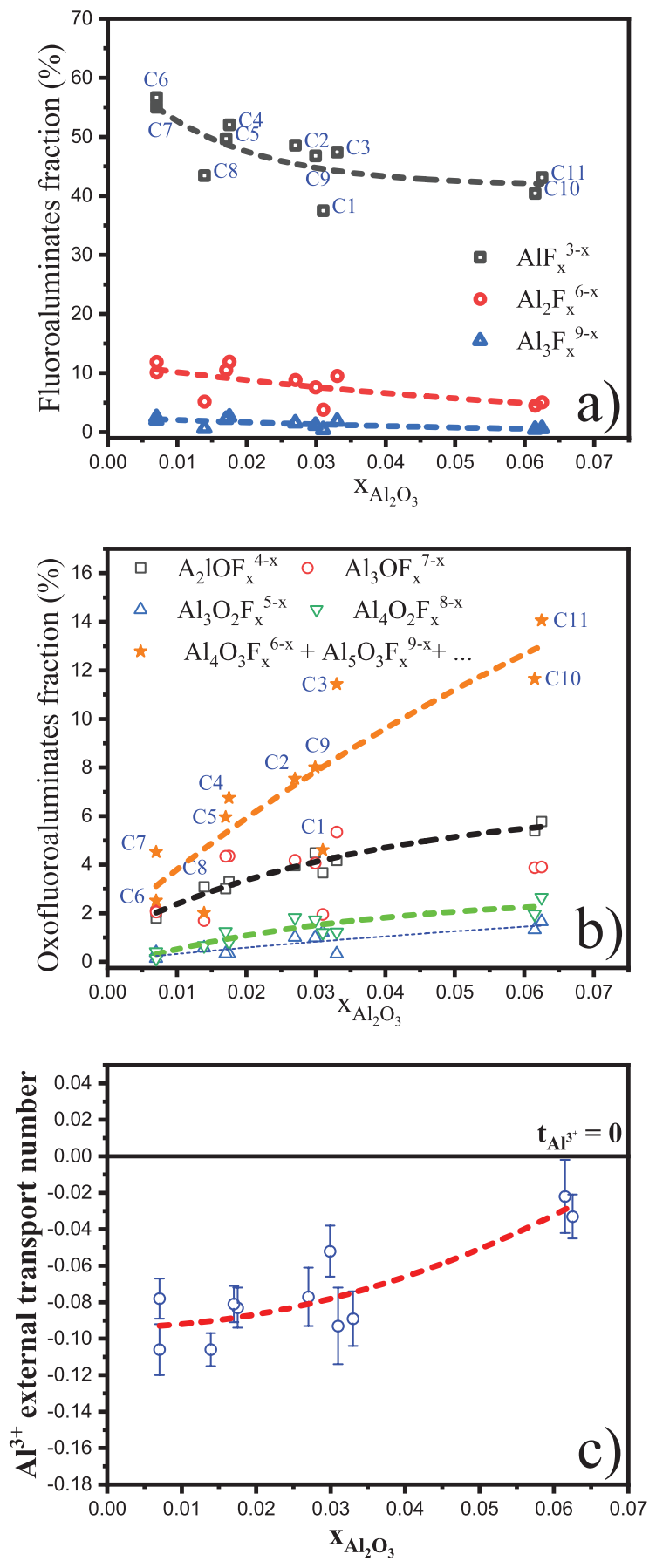

Figure 4: Calculated fraction of fluoroaluminates (a) and fluoroaluminates (b) as a function of alumina molar fraction. The $\mathrm{Al}^{3^{+}}$transference number as a function of alumina molar fraction is shown in figure (c). 


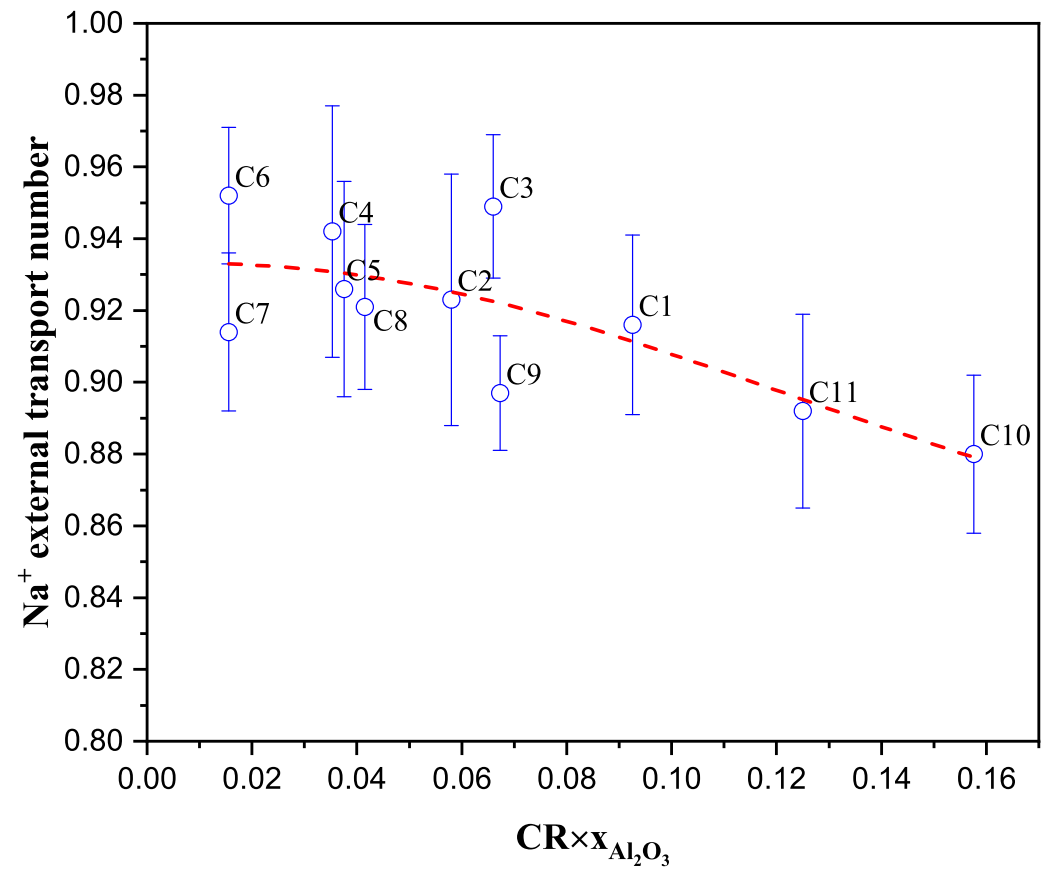

Figure 5: Evolution of the $\mathrm{Na}^{+}$transference number as a function of the product $\mathrm{CR} \times \mathrm{X}_{\mathrm{Al}_{2} \mathrm{O}_{3}}$. The dashed line represents a linear fitting of $t_{\mathrm{Na}^{+}}$vs. $\mathrm{CR} \times \mathrm{X}_{\mathrm{Al}_{2} \mathrm{O}_{3}}$.

transference number can be represented as: $\partial t_{F^{-}}^{i o n} / \partial x_{F^{-}} \simeq 1.39 .10^{-5}$. The local structurepartial conductivity relationship observed for $\mathrm{F}^{-}$in alumina containing cryolitic is very close to that observed in simple cryolitic melts (i.e NaF-AlF3) ${ }^{10}$ for which the amount of free $\mathrm{F}^{-}$ decreases from $40 \%$ for $C R=3$ to $15 \%$ for $C R=3$, while the corresponding $\mathrm{F}^{-}$transference number decreases from 0.18 to 0.13 . In a nutshell, whether it is for simple or alumina containing cryolitic melts, the transference number of $\mathrm{F}^{-}$mainly depends on the amount of free $\mathrm{F}^{-}$. Note that, from both a simulation and experimental point of view, in pure NaF, the $\mathrm{F}^{-}$transference number is about $0.3^{10,15}$ while simulations have shown that above a CR of about 1, the transference number of $\mathrm{F}^{-}$is almost null as no free $\mathrm{F}^{-}$remains in the melt. This indicates a non linear behaviour of $t_{F^{-}}^{i o n}$ vs. $x_{F^{-}}$beyond the range $2 \leq C R \leq 3$.

The transference number of $\mathrm{Al}^{3^{+}}$is represented in Figure 4 along with the evolution of the amount of both fluoroaluminates and oxofluoroaluminates complex anions as a function of alumina molar fraction. The transference number of $\mathrm{Al}^{3^{+}}$is negative for all studied cryolitic melts. As explained above, this is because aluminium is present in the melts in 
the form of an anionic complex, therefore they effectively migrate towards the anode instead of the cathode. The most significant element in the behaviour of the $\mathrm{Al}^{3+}$ transference number is that it tends towards zero as $\mathrm{x}_{\mathrm{Al}_{2} \mathrm{O}_{3}}$ increases. The amount of fluoroaluminates anion complexes decreases as the amount of alumina increases (Figure 4a) in the favour of oxofluoroaluminates (Figure 4b) which are larger and heavier, having thus, in principle, a smaller mobility than that of of fluoroaluminates: in particular $\mathrm{AlF}_{x}^{3-x}$. Moreover, one can note that higher order oxofluoroaluminates $\left[\mathrm{Al}_{4} \mathrm{O}_{3} \mathrm{~F}_{x}\right]^{6-x}$ and $\left[\mathrm{Al}_{5} \mathrm{O}_{3} \mathrm{~F}_{x}\right]^{9-x}$ show the most important growth rate with $\mathrm{x}_{\mathrm{Al}_{2} \mathrm{O}_{3}}$, which is the major contributing factor to the critical decrease of the $\mathrm{Al}^{3^{+}}$transference number.

From the above, the transference number of $\mathrm{Na}^{+}$should therefore depend on both $\mathrm{CR}$ and $\mathrm{x}_{\mathrm{Al}_{2} \mathrm{O}_{3}}$. When CR increases, $t_{\mathrm{Na}^{+}}^{i o n}$ decreases to the benefit of $t_{\mathrm{F}^{-}}^{i o n}$, with limiting values of of 0.7 and 0.3 respectively for $\mathrm{Na}^{+}$and $\mathrm{F}^{-}$in pure molten $\mathrm{NaF}$. As $\mathrm{x}_{\mathrm{Al}_{2} \mathrm{O}_{3}}$ increases, $t_{\mathrm{Al}^{3+}}^{i o n}$ increases (becoming less and less negative), tending towards 0 like $\mathrm{O}^{2^{-}} \cdot t_{A l^{+}}^{i o n}$ drastically reduces its contribution to the total conductivity, leading to a relative decrease of the $\mathrm{Na}^{+}$transference number which is equivalent to the relative increase of the $\mathrm{F}^{-}$transference number. In other words, at a certain alumina level, only $\mathrm{Na}^{+}$and $\mathrm{F}^{-}$contribute to the total conductivity and their transference numbers tend to an ideal value, i.e in the absence of interferences due to short range ordering, observed in molten NaF. From a microscopic point of view, the electrostatic interferences from $\mathrm{Al}^{3^{+}}$, which benefited $\mathrm{Na}^{+}$and quantified by $\omega_{\mathrm{Na}-\mathrm{Al}}^{\mathrm{Na}}$, are considerably reduced with the increase of alumina in the melt leading to a decrease of $t_{\mathrm{Na}^{+}}^{\text {. }}$. To combine both the effect of $\mathrm{CR}$ and $\mathrm{x}_{\mathrm{Al}_{2} \mathrm{O}_{3}}$ upon the transference number of $\mathrm{Na}^{+}$, we have represented its evolution in Figure 5 as a function of the product $\mathrm{CR} \times \mathrm{x}_{\mathrm{Al}_{2} \mathrm{O}_{3}}$. The behaviour is found to be nearly linear. Note that for C1, it was possible to compare the calculated transference number of $\mathrm{Na}^{+}$with the experimental measurement of Tual and Rolin. ${ }^{8,9}$ For melts with a $\mathrm{CR}=3 \pm 0.33$ and 5 wt.\% of alumina, which is close to $\mathrm{C} 1$ composition, Tual and Rolin determined via Hittorf's method that: $t_{N a^{+}}^{i o n, E x p}=0.95 \pm 0.05$. Their experimental results are in good agreement with our calculated value for C1 (0.916). 


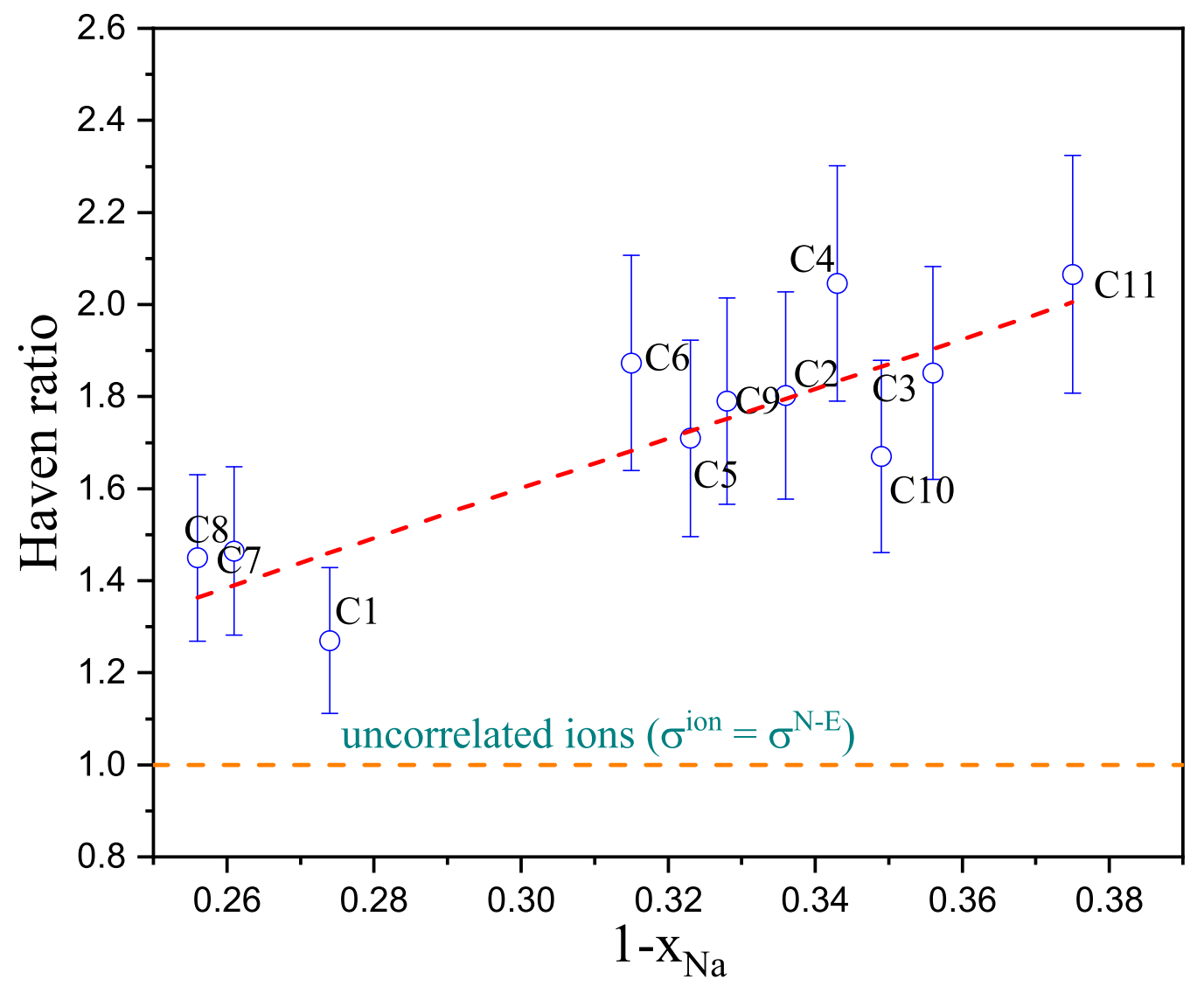

Figure 6: Evolution of the Haven ratio $\left(H R=\sigma^{N-E} / \sigma^{i o n}\right)$ as a function of CR of the 11 studied cryolitic melts. The dashed line represents a linear fitting of the calculated $H R$ for each composition, C1 to C11. 
As mentioned before, from a microscopic point of view, the charge-charge electrostatic interferences play a major role in the ionic conductivity of cryolitic melts. In the absence of electrostatic interferences, the total ionic conductivity would be identical to the NernstEinsten conductivity. The Haven ratio, $H R=\sigma^{N-E} / \sigma^{i o n},{ }^{45}$ defines the total effect of the electrostatic interferences upon ionic conductivity. In general, in molten ionically bonded systems, $H R$ is greater than 1 . In other words, the electrostatic interferences overall mitigate the ions mobility. The calculated Haven ratio of the 11 cryolitic melts are presented in Figure 6. $H R$ increase almost linearly with $1-x_{N a}$, i.e the more species interact with $\mathrm{Na}^{+}$, the larger is the Haven ratio. $\mathrm{Na}^{+}$fully benefits from the electrostatic interferences at the expense of other ions in the cryolitic melts. Increasing the amount of ions interfering with $\mathrm{Na}^{+}$reduces significantly their apparent charge diffusion compared to their tracer diffusion.

Lastly, let us briefly discuss the electronic conductivity. Unlike academic experiments (like the current work and the work of Tual and Rolin), in industrial electrolysis cells, up to $0.5 \mathrm{~mol} \%$ of metal, mainly $\mathrm{Al}$ and $\mathrm{Na}$, can be dissolved in the cryolitic bath. The electrons mobility is orders of magnitude higher than that of ions. Consequently, this small amount of metals is enough to significantly increase the electrical conductivity of the electrolyte. For a standard bath $\left(\mathrm{Na}_{3} \mathrm{AlF}_{6}-11\right.$ wt. $\% \mathrm{AlF}_{3}-2.5$ wt. $\% \mathrm{Al}_{2} \mathrm{O}_{3}-5$ wt. $\left.\% \mathrm{CaF}_{2}\right)$ it can be increased by up to $30 \% .{ }^{37}$ Therefore, the presence of dissolved metals in cryolitic melts may also significantly decrease the transference number of $\mathrm{Na}^{+}$due to a possible large electronic conductivity.

\section{Conclusion and Perspective}

The partial charge transport properties of cryolitic melts for 11 compositions of interest in aluminium primary production have been calculated via a series of equilibrium molecular dynamics simulations based on a force field parameterized from first-principles. The predictive capability of the simulations have been clearly demonstrated on the values of total ionic conductivity for which experimental data are available. The partial charge transport prop- 
erties have been extensively discussed through their local structure dependence. It has been shown that both CR and alumina molar fraction have an important impact on the anion complexes evolution which is reflected on the evolution of the transference number of ions in the cryolitic melts. $\mathrm{O}^{2^{-}}$ions, present in heavy and large oxofluoroaluminates, have an almost null transference number. In other words the contribution of $\mathrm{O}^{2^{-}}$to the total conductivity is insignificant. It was demonstrated that the transference number of $\mathrm{F}^{-}$essentially depends on the free $\mathrm{F}^{-}$fraction, itself depending almost entirely on CR. As a positive charge complexed in negative complex anions, $\mathrm{Al}^{3^{+}}$has a negative transport number. However, we have shown that $\mathrm{Al}^{3^{+}}$transference number decreases drastically and tends to 0 when the alumina molar fraction increases. When the amount of alumina dissolved in cryolitic melts increases, the concentration of heavy and large oxofluoroaluminates drastically increases at the expense of lighter and smaller fluoroaluminates, resulting in the complexion of $\mathrm{Al}^{3^{+}}$in anion complexes with negligible mobility, making its transference number tend to that of $\mathrm{O}^{2-}$. Finally, it has been shown that the $\mathrm{Na}^{+}$transference number decreases as both amounts of free $\mathrm{F}^{-}$and oxofuoroalimates increase. Formally, the $\mathrm{Na}^{+}$transference number decreases almost linearly with the product $\mathrm{CR} \times x_{\mathrm{Al}_{2} \mathrm{O}_{3}}$. Lastly, the calculated deviation from the Nernst-Einstein conductivity, which gives the measure of the effect of electrostatic interferences between each ions upon the conductivity was found to increase linearly with $1-\mathrm{x}_{\mathrm{Na}}$.

From the application point of view, these calculations will benefit to the aluminium primary production industries, by helping to design and improve electrolysis cells , in particular in their efforts to reduce industrial greenhouse gases emissions.

\section{Acknowledgements}

This research was supported by funds from the Natural Sciences and Engineering Research Council of Canada (NSERC), Rio Tinto Aluminium, Alcoa, Hydro Aluminium, Constellium. Computations were made on the supercomputer Béluga at the École de technologie 
supéérieure, managed by Calcul-Québec and Compute Canada.

\section{References}

(1) Salanne, M.; Simon, C.; Groult, H.; Lantelme, F.; Goto, T.; Barhoun, A. Transport in molten $\mathrm{LiF}-\mathrm{NaF}-\mathrm{ZrF} 4$ mixtures: A combined computational and experimental approach. Journal of Fluorine Chemistry 2009, 130, 61 - 66, Fluorine and Nuclear Energy.

(2) Rollet, A.-L.; Sarou-Kanian, V.; Bessada, C. Measuring Self-Diffusion Coefficients up to $1500 \mathrm{~K}$ : A Powerful Tool to Investigate the Dynamics and the Local Structure of Inorganic Melts. Inorganic Chemistry 2009, 48, 10972-10975, PMID: 19863113.

(3) Rollet, A.-L.; Sarou-Kanian, V.; Bessada, C. Self-diffusion coefficient measurements at high temperature by PFG NMR. C. R. Chim. 2010, 13, 399-404.

(4) Gobet, M.; Sarou-Kanian, V.; Rollet, A.-L.; Salanne, M.; Simon, C.; Bessada, C. Transport properties in cryolitic melts: NMR measurements and molecular dynamics calculations of self-diffusion coefficients. ECS Trans. 2010, 33, 679-684.

(5) Hives, J.; Fellner, P.; Thonstad, J. Transference numbers in Na(K) cryolite-based systems. Molten Salts Chem. Technol. 2014; pp 95-101.

(6) Fellner, P.; Hives, J.; Thonstad, J. Transport numbers in the molten system NaF-KFAlF3-Al2O3. Light Met. (Hoboken, NJ, U. S.) 2011, 513-516.

(7) Frank, W. B.; Foster, L. M. Investigation of transport phenomena in the cryolitealumina system by means of radioactive tracers. J. Phys. Chem. 1957, 61, 1531-6.

(8) Tual, A.; Rolin, M. Ionic transference numbers in cryolite-alumina melts according to the principle of Hittorf's method. I. Putting the method into effect. Electrochim. Acta $1972,17,1945-54$. 
(9) Tual, A.; Rolin, M. Study of ionic transference numbers in molten cryolite-alumina mixtures according to the principle of Hittorf's method. II. Results. Electrochim. Acta 1972, 17, 2277-91.

(10) Gheribi, A. E.; Machado, K.; Zanghi, D.; Bessada, C.; Salanne, M.; Chartrand, P. On the determination of ion transport numbers in molten salts using molecular dynamics. Electrochimica Acta 2018, 274, 266 - 273.

(11) Gheribi, A. E.; Serva, A.; Salanne, M.; Machado, K.; Zanghi, D.; Bessada, C.; Chartrand, P. Study of the Partial Charge Transport Properties in the Molten Alumina via Molecular Dynamics. ACS Omega 2019, 4, 8022-8030.

(12) Rapaport, D. C. The Art of Molecular Dynamics Simulation; Cambridge University Press: New York, NY, USA, 1996.

(13) Feng, N. X.; Kvande, H. Dissociation equilibria in molten cryolite: the presence of pentaflueroaluminate(2-) ions. Acta Chem. Scand., Ser. A 1986, A40, 622-30.

(14) Grjotheim, K.; Matiasovsky, K.; Myhre-Andersen, S.; Øye, H. Transport numbers in molten fluorides-I. Sodium fluoride. Electrochimica Acta 1968, 13, 91 - 98.

(15) Grjothem, K.; Haugerød, O.; Stamnes, H.; Øye, H. Transport numbers in molten fluorides-II. Mixtures between $\mathrm{NaF}-\mathrm{NaCl}$ and $\mathrm{NaF}-\mathrm{NaBr}$. Electrochimica Acta 1972, 17 , $1547-1556$.

(16) Machado, K.; Zanghi, D.; Salanne, M.; Stabrowski, V.; Bessada, C. Anionic Structure in Molten Cryolite-Alumina Systems. The Journal of Physical Chemistry C 2018, 122, $21807-21816$.

(17) Norberg, S. T.; Ahmed, I.; Hull, S.; Marrocchelli, D.; Madden, P. A. Local structure and ionic conductivity in the Zr2Y2O7-Y3NbO7 system. J. Phys.: Condens. Matter 2009, 21, 215401/1-215401/11. 
(18) Castiglione, M. J.; Wilson, M.; Madden, P. A. Polarization effects in the simulation of lead (II) fluoride. J. Phys.: Condens. Matter 1999, 11, 9009-9024.

(19) Madden, P. A.; Heaton, R.; Aguado, A.; Jahn, S. From first-principles to material properties. Journal of Molecular Structure: $\{$ THEOCHEM\} 2006, 771, 9 - 18.

(20) Tang, K. T.; Toennies, J. P. An improved simple model for the van der Waals potential based on universal damping functions for the dispersion coefficients. The Journal of Chemical Physics 1984, 80, 3726-3741.

(21) Salanne, M.; Madden, P. A. Polarization effects in ionic solids and melts. Molecular Physics 2011, 109, 2299-2315.

(22) Jabes, B. S.; Chakravarty, C. Relating composition, structural order, entropy and transport in multi-component molten salts. The Journal of Chemical Physics 2012, 136, 144507 .

(23) Hoover, W. G.; Holian, B. L. Kinetic moments method for the canonical ensemble distribution. Physics Letters A 1996, 211, 253 - 257.

(24) Martyna, G. J.; Tobias, D. J.; Klein, M. L. Constant pressure molecular dynamics algorithms. The Journal of Chemical Physics 1994, 101, 4177-4189.

(25) Yeh, I.-C.; Hummer, G. System-Size Dependence of Diffusion Coefficients and Viscosities from Molecular Dynamics Simulations with Periodic Boundary Conditions. J. Phys. Chem. B 2004, 108, 15873-15879.

(26) Salanne, M.; Simon, C.; Turq, P.; Madden, P. A. Conductivity-Viscosity-Structure: Unpicking the Relationship in an Ionic Liquid. The Journal of Physical Chemistry B 2007, 111, 4678-4684.

(27) Lacassagne, V.; Bessada, C.; Florian, P.; Bouvet, S.; Ollivier, B.; Coutures, J.-P.; 
Massiot, D. Structure of High-Temperature NaF-AlF3-Al2O3 Melts: A Multinuclear NMR Study. The Journal of Physical Chemistry B 2002, 106, 1862-1868.

(28) Gheribi, A. E.; Salanne, M.; Chartrand, P. Formulation of Temperature-Dependent Thermal Conductivity of NaF, B-Na3AlF6, Na5Al3F14, and Molten Na3AlF6 Supported by Equilibrium Molecular Dynamics and Density Functional Theory. The Journal of Physical Chemistry C 2016, 120, 22873-22886.

(29) Gheribi, A.; Corradini, D.; Dewan, L.; Chartrand, P.; Simon, C.; Madden, P.; Salanne, M. Prediction of the thermophysical properties of molten salt fast reactor fuel from first-principles. Molecular Physics 2014, 112, 1305-1312.

(30) Gheribi, A. E.; Torres, J. A.; Chartrand, P. Recommended values for the thermal conductivity of molten salts between the melting and boiling points. Solar Energy Materials and Solar Cells 2014, 126, $11-25$.

(31) Gheribi, A. E.; Chartrand, P. Thermal conductivity of molten salt mixtures: Theoretical model supported by equilibrium molecular dynamics simulations. The Journal of Chemical Physics 2016, 144 .

(32) Bale, C.; Bélisle, E.; Chartrand, P.; Decterov, S.; Eriksson, G.; Gheribi, A.; Hack, K.; Jung, I.-H.; Kang, Y.-B.; Melançon, J. et al. FactSage thermochemical software and databases, 2010-2016. Calphad 2016, 54, 35 - 53.

(33) Flyvbjerg, H.; Petersen, H. G. Error estimates on averages of correlated data. The Journal of Chemical Physics 1989, 91, 461-466.

(34) Pranami, G.; Lamm, M. H. Estimating Error in Diffusion Coefficients Derived from Molecular Dynamics Simulations. J. Chem. Theory Comput. 2015, 11, 4586-4592.

(35) Robelin, C.; Chartrand, P. A Density Model Based on the Modified Quasichemical 
Model and Applied to the NaF-AlF3-CaF2-Al2O3 Electrolyte. Metallurgical and Materials Transactions B 2007, 38, 881-892.

(36) Robelin, C.; Chartrand, P. A viscosity model for the (NaF+AlF3+CaF2+Al2O3) electrolyte. The Journal of Chemical Thermodynamics 2011, 43, $764-774$.

(37) Thonstad, J.; Fellner, P.; Haarberg, G. M.; Hives, J.; Kvarde, H.; Sterten, A. Aluminium Electrolysis: Fundamentals of the Hall-Héroult Process; Aluminium-Verlag, 2001.

(38) Wang, X.; Peterson, R. D.; Tabereaux, A. T. Electrical conductivity of cryolitic melts. Light Met. (Warrendale, Pa.) 1992, 481-8.

(39) Stokes, R. H.; Levien, B. J. The osmotic and activity coefficients of zinc nitrate, zinc perchlorate, and magnesium perchlorate. Transference numbers in zinc perchlorate solutions. J. Am. Chem. Soc. 1946, 68, 333-7.

(40) Jorne, J.; Ho, W. T. Transference numbers of zinc in zinc-chloride battery electrolytes. J. Electrochem. Soc. 1982, 129, 907-12.

(41) Ferry, A.; Doeff, M. M.; DeJonghe, L. C. Transport property measurements of polymer electrolytes. Electrochim. Acta 1998, 43, 1387-1393.

(42) Doeff, M. M.; Georen, P.; Qiao, J.; Kerr, J.; De Jonghe, L. C. Transport properties of a high molecular weight poly(propylene oxide)-LiCF3SO3 system. J. Electrochem. Soc. 1999, 146, 2024-2028.

(43) Pesko, D. M.; Timachova, K.; Bhattacharya, R.; Smith, M. C.; Villaluenga, I.; Newman, J.; Balsara, N. P. Negative Transference Numbers in Poly(ethylene oxide)-Based Electrolytes. J. Electrochem. Soc. 2017, 164, E3569-E3575.

(44) Ma, Y.; Doyle, M.; fuller, t. F.; Doeff, M. M.; De Jonghe, L. C.; Newman, J. The measurement of a complete set of transport properties for a concentrated solid polymer electrolyte solution. J. Electrochem. Soc. 1995, 142, 1859-68. 
(45) Compaan, K.; Haven, Y. Correlation factors for diffusion in solids. Part 2.- Indirect interstitial mechanism. Trans. Faraday Soc. 1958, 54, 1498-1508. 